Japanese Journal of Applied Physics, 26 (7) (1987) 1069-1072

\title{
Fluorescence from Pearls and Shells of Black Lip Oyster, Pinctada Margaritifera, and Its Contribution to the Distinction of $M$ other Oysters Used in Pearl Culture
}

Tadaki Miyoshi, Yasunori Matsuda ${ }^{1}$ and Hiroshi Komatsu ${ }^{1}$

Technical College, Yamaguchi U niversity, Tokiwadai, U be, Yamaguchi 755

${ }^{1}$ Pearl Research laboratory, K. MIKIMOTO \& Co., Ltd., Aobadai, M eguro-ku, Tokyo 153

(Received February 5, 1987; accepted April 25, 1987)

The fluorescence of pearls and shells of Pinctada margaritifera (black lip oyster) has been measured in order to distinguish the species of mother oysters which produce those pearls. A distinction is possible for pearls of P. margaritifera from those of Pinctada fucata and Pinctada maxima using a difference in the fluoresence spectra; this difference is caused by the presence or absence of porphyrin in pearls, respectively. However, the distinction between P. margaritifera and Pteria penguin, both of which have porphyrin in nacre, is difficult by measuring the fluorescence spectra. It is achieved by measuring the optical reflection spectra, since P. margaritifera shows a peculiar dip at $700 \mathrm{~nm}$. 


\section{$\S 1$. Introduction}

Since Kokichi Mikimoto succeeded in inventing a technique for half-pearl culturing in 1893, Pinctada fucata (Japan's Akoya oyster) has been used as a mother oyster. This oyster is the most famous and important in present-day pearl culturing. However, several mother oysters are used in pearl culturing: Pinctada maxima (yellow lip oyster), Pinctada margaritifera (black lip oyster), Pteria penguin (mabe), genus Haliotis (abalone), Hyriopsis shlegeli et al. Nondestructive methods for distinguishing mother oysters have been interesting from practical point of view, owing to the fact that the commercial value of pearls depends on the mother oysters. Especially, an exact distinction of pearls of P. margaritifera is important and necessary for the pearl buisiness, since pearls produced from P. margaritifera have a high commercial value compared with those from other mother oysters.

It has been reported that pearls and shells of P. margaritifera show a peculiar dip at $700 \mathrm{~nm}$ in an optical reflection spectrum and that a distinction is possible using this characteristic. ${ }^{1)}$ In previous papers, ${ }^{2,3)}$ we have discussed the fact that pearls of P. fucata, P. maxima and P. penguin can be distinguished from each other using various differences in the fluorescence spectra under $\mathrm{N}_{2}$ laser and ordinary lamp excitation. In this paper, we attempt to apply measurements of the fluorescence spectra for a distinction of pearls of P. margaritifera from those of other pearl oysters, and to examine the fluorescent components of nacre of this oyster.

\section{§2. Experimental Procedure}

The fluorescence spectra have been measured at room temperature with the following apparatus (similar to that described in ref. 3). The excitation source was a pulsed $\mathrm{N}_{2}$ laser (NDC JS-1000L; $\lambda=337.1 \mathrm{~nm}$, pulse duration $=5 \mathrm{~ns}$, repetition rate $=4$ $\mathrm{Hz}$ ). The laser beam was set at an angle of about $50^{\circ}$ off the normal incidence to the plane of a sample and was focused on a spot about $1 \mathrm{~mm}^{2}$ in area by a quartz lens. The peak intensity of the laser light on the sample was about $50 \mathrm{~kW} / \mathrm{cm}^{2}$. Fluorescence was observed at $90^{\circ}$ to the laser beam and was focused on the entrance slit of a $50 \mathrm{~cm}$ monochromator (Oyo Bunko ASI-50S) by a glass lens. Time-integrated and time-resolved fluorescence spectra were measured with a monochromator, 
a photomultiplier (Hamamatsu R955), a boxcar integrator (NF Circuit Design Block BX-531) and a recorder. Ordinary fluorescence spectra and excitation spectra have been measured with a spectrofluorophotometer (Japan Spectroscopic FP-770). The apparatus constant was not corrected for the ordinary fluorescence spectra. Optical absorption and transmission spectra have been measured with a double-beam spectrophotometer (Japan Spectroscopic, UVIDEC-610C) and optical reflection spectra were measured with the spectrophotometer using an integrating sphere.

In this study, pearls and shells of P. margaritifera were used as specimens; pearls were collected in Tahiti Island and shells were collected in Ishigaki Island, Okinawa. This mother oyster produces pearls with various colours: black, grey and white. Among these colours, black and grey are caused by colouring matter in nacre, which is the surface layer part of pearls and shells. The colour of most grey pearls is caused by brownish organic substances existing between translucent nacre and a pearl nucleus. In this experiment, we mainly adopt the nacre of shell, since the nacre of shell has the same chemical composition as the pearl itself; also, shells of P. margaritifera are obtained more easily than pearls. It has been reported that nacre of mother oysters shows a similar fluorescence spectrum to that of a pearl produced from the same species as the mother oyster. ${ }^{3)}$ Fluorescence from shells of P. maxima, P. fucata and P. penguin were also measured in order to compare the fluorescence spectra with that of $P$. margaritifera.

A decalcified solution of nacre was also investigated in order to identify the fluorescent components of pearls and shells. The shells used in this study were P. margaritifera collected in Ishigaki Island, Okinawa. The periostracum and the prismatic layer of valves were removed with a motor-driven whetstone. The cleaned black nacre was then ground with a mortar, and decalcified with $10 \% \quad \mathrm{Na}_{2}$ EDTA (disodium ethylendiamine tetraacetate). The EDTA was removed by exhaustive dialysis against distilled water. The insoluble matrix was collected by centrifugation at $3000 \mathrm{rpm}$ for 30 min. The supernatant fluid from this centrifugation was concentrated by evaporation under reduced pressure; then, the soluble matrix was chromatographed on a $1.6 \mathrm{~cm}$ x 25 cm Sephadex G-25 column with 0.05 mol/1 phosphate buffer. Two ultraviolet-absorbing $(280 \mathrm{~nm})$ peaks (such as Fraction 1 and Fraction 2) were eluted. Fraction 1, excluded at 
the void volume from this column, represented deep brown; it was considered that this fraction predominates the colour of nacre. Fraction 2 showed a faint-yellow colour and had lower molecular weights, since it was excluded much later than Fraction 1. The optical absorption spectra and fluorescence spectra were measured for these specimens.

\section{§3. Results and Discussion}

Figure 1 shows the time-integrated fluorescence spectra of nacre of shells of pearl oysters; black and white shells of P. margaritifera, reddish-brown shell of P. penguin, a white shell of P. maxima and a yellow shell of P. fucata. P. margaritifera show two fluorescent peaks at about 450 and $620 \mathrm{~nm}$ in black shells; the $620 \mathrm{~nm}$ peak did not appear in white shells. The $620 \mathrm{~nm}$ peak was not observed in the shells of P. maxima and P. fucata. Pearls of these mother oysters were also measured, and it was observed that pearls of each mother oyster show a similar fluorescence spectra to shells of that oyster. Thus, a distinction is possible for black pearls of $P$. margaritifera from those of $P$. maxima and P. fucata using this difference in the fluorescence spectra. On the other hand, a distinction between P. margaritifera and P. penguin may be impossible by measuring the fluorescence spectra, since both shells show similar fluorescence spectra. Since the $620 \mathrm{~nm}$ peak for the black shell of P. margaritifera is similar to that observed in $P$. penguin, both shells of $P$. margaritifera and P. penguin may have the same colouring matter. It is also apparent that the fluorescence intensity of the $620 \mathrm{~nm}$ peak depends on the colour of shells. The properties of the colouring matter were examined, and the results are as follows.

The excitation spectrum was measured using a spectrofluorophotometer. As shown in Fig. 2, a peak appears at $400 \mathrm{~nm}$ under the following conditions; in the excitation spectrum, the observed wavelength was fixed at $620 \mathrm{~nm}$ (fluorescence peak of black shell), and the excitation wavelength was scanned. The abscissa represents excitation wavelengths. This result indicates that the colouring matter has an absorption peak at $400 \mathrm{~nm}$.

The optical absorption spectra were measured for decalcified solutions (Fraction 1 and Fraction 2) of coloured nacre in order to examine this absorption peak. As shown in Fig. 3, the absorption peak was observed at $400 \mathrm{~nm}$ in Fraction 2; this suggests that 
Fraction 2 contains porphyrin, since the $400 \mathrm{~nm}$ absorption is considered to be the Soret band which characterizes porphyrins. ${ }^{4)}$ Figure 4 shows the time-resolved fluorescence spectra of Fraction 2. While the relative intensity of the $620 \mathrm{~nm}$ peak is weak for a short delay time, it increases with increasing delay time. This result indicates that the $620 \mathrm{~nm}$ peak has a long decay time. This decay time was estimated to be about 12 ns from the time-resolved spectra and is in agreement with the reported value for porphyrin. ${ }^{5)}$ These results indicate that the $620 \mathrm{~nm}$ peak is caused by porphyrin.

The properties of the colouring matter are similar to those for P. penguin: ${ }^{3)}$ fluorescence peak at $620 \mathrm{~nm}$, absorption peak at $400 \mathrm{~nm}$ and decay time of $12 \mathrm{~ns}$. It has been reported that porphyrin is contained in shells of P. margaritifera and P. penguin. ${ }^{6}$

Figure 5 shows the fluorescence spectra of the white shell, which is the same specimen as that used in Fig. 1, and a grey pearl of P. margaritifera under $400 \mathrm{~nm}$ excitation using the spectrofluorophotometer. While the $620 \mathrm{~nm}$ peak was not observed in the white shell under $\mathrm{N}_{2}$ laser excitation (Fig. 1), it was detected in this spectrum in Fig. 5. This result is similar to that of $P$. penguin (as previously reported in ref. 3). Moreover, the $620 \mathrm{~nm}$ peak was observed in the spectrum for the grey pearl. Thus, the pearls and shells examined in this study contain porphyrin in nacre. The colour of the grey pearl (Fig. 5) is caused by brownish organic substrances between nacre and the pearl nucleus.

Pearls and shells of P. margaritifera and P. penguin show the $620 \mathrm{~nm}$ peak; it is therefore difficult to make a distinction between pearls of $\mathrm{P}$. margaritifera and $\mathrm{P}$. penguin by measuring the fluorescence spectra. On the other hand, pearls and shells of these oysters show different refection spectra (Fig.6). The pearl and shells of P. margaritifera show a $700 \mathrm{~nm}$ dip, while the shell of $P$. penguin does not. The $700 \mathrm{~nm}$ dip was not observed in the transmission spectrum of a nacreous lamella of black nacre (Fig. 7); the lamellas, which are about $0.3 \mathrm{~mm}$ thick, were made using a motor-driven whetstone from black and white nacre of shells of P. margaritifera On the other hand, the absorption peak was not observed for chromatographed fractions of the decalcified solution shown in Fig. 3. This suggests that the $700 \mathrm{~nm}$ dip is related to an insoluble matrix, which is called conchiolin; it was obtained as a residue in the decalcification procedure of nacre. However, the $700 \mathrm{~nm}$ dip was not observed in the reflection 
spectrum of conchiolin (Fig. 8). Therefore, the cause of the $700 \mathrm{~nm}$ dip has not been clarified. It should be studied further in the future.

In summary, the fluorescence spectra of pearls and shells of mother oysters have been measured. A distinction is possible for pearls of P. margaritifera from those of P. maxima and P. fucata using a peculiar peak at $620 \mathrm{~nm}$, which is attributable to porphyrin. On the other hand, the distinction between P. margaritifera and P. penguin is difficult using the fluorescence method. Nevertheless, the fluorescence method is useful for the distinction of mother oysters from a practical point of view, since the number of pearls produced is extremely small for P. penguin.

\section{Acknowledgement}

The authors would like to thank President S. Tokashiki, Ryukyu Pearls Co., Ltd., for supplying shells of P. margaritifera. 
R eferences

1) H. Komatsu and S. Akamatsu: J. Gemmological Soc. Jpn. 5 (1979) No. 4, 3 [in Japanese].

2) T. Miyoshi, Y. Matsuda and H. Komatsu: Jpn. J. Appl. Phys. 25 (1986) 1606.

3) T. Miyoshi, Y. Matsuda and H. Komatsu: Jpn. J. Appl. Phys. 26 (1987) 578.

4) J. E. Falk: Porphyrins and Metalloporphyrins (Elsevier, Amsterdam, 1964) p. 87.

5) Y. Onoue, K. Hiraki and Y. Nishikawa: Bunseki Kagaku 31 (1982) 169 [in Japanese].

6) R. Tixier: Ann. L'Inst. Oceanographique 22 (1945) 343. 


\section{Figure captions}

Fig. 1. Time-integrated fluorescence spectra of nacre of shells of several mother oysters at $300 \mathrm{~K}$ under $\mathrm{N}_{2}$ layer excitation. Peak intensities are normalized.

Fig. 2. Excitation spectrum of the $620 \mathrm{~nm}$ peak of the black shell of P. margaritifera using a spectrofluorophotometer. The observed wavelength is fixed at $620 \mathrm{~nm}$ (fluorescence peak of black shell), and the excitation wavelength is scanned. The abscissa represents the excitation wavelengths.

Fig. 3. Optical absorption spectra of decalcified solutions (Fraction 1 and Fraction 2) of black shell of P. margaritifera. Optical-path length of the sample cell is $10 \mathrm{~mm}$.

Fig. 4. Time-resolved fluorescence spectra of Fraction 2. Peak intensity ratios of the 620 $\mathrm{nm}$ peak are as follows: 0.5 (delay time $\mathrm{t}=-2 \mathrm{~ns}), 1(8 \mathrm{~ns}), 0.4(18 \mathrm{~ns})$. The inset shows the transient characteristics of laser pulse.

Fig. 5. Fluorescence spectra of the white shell and a grey pearl of $P$. margaritifera under $400 \mathrm{~nm}$ excitation using a spectrofluorophotometer.

Fig. 6. Optical reflection spectra of a pearl and shells of P. margaritifera (solid curve) and a reddish-brown shell of $P$. penguin (dashed curve).

Fig. 7. Optical transmission spectra of the nacreous lamellas of black and white shells of P. margaritifera; the lamellas, about $0.3 \mathrm{~mm}$ thick, were produced using a motor-driven whetstone from nacre.

Fig. 8. Optical reflection spectrum of conchiolin of P. margaritifera; conchiolin was obtained as a residue in the decalcification procedure of nacre. 
Fig. 1

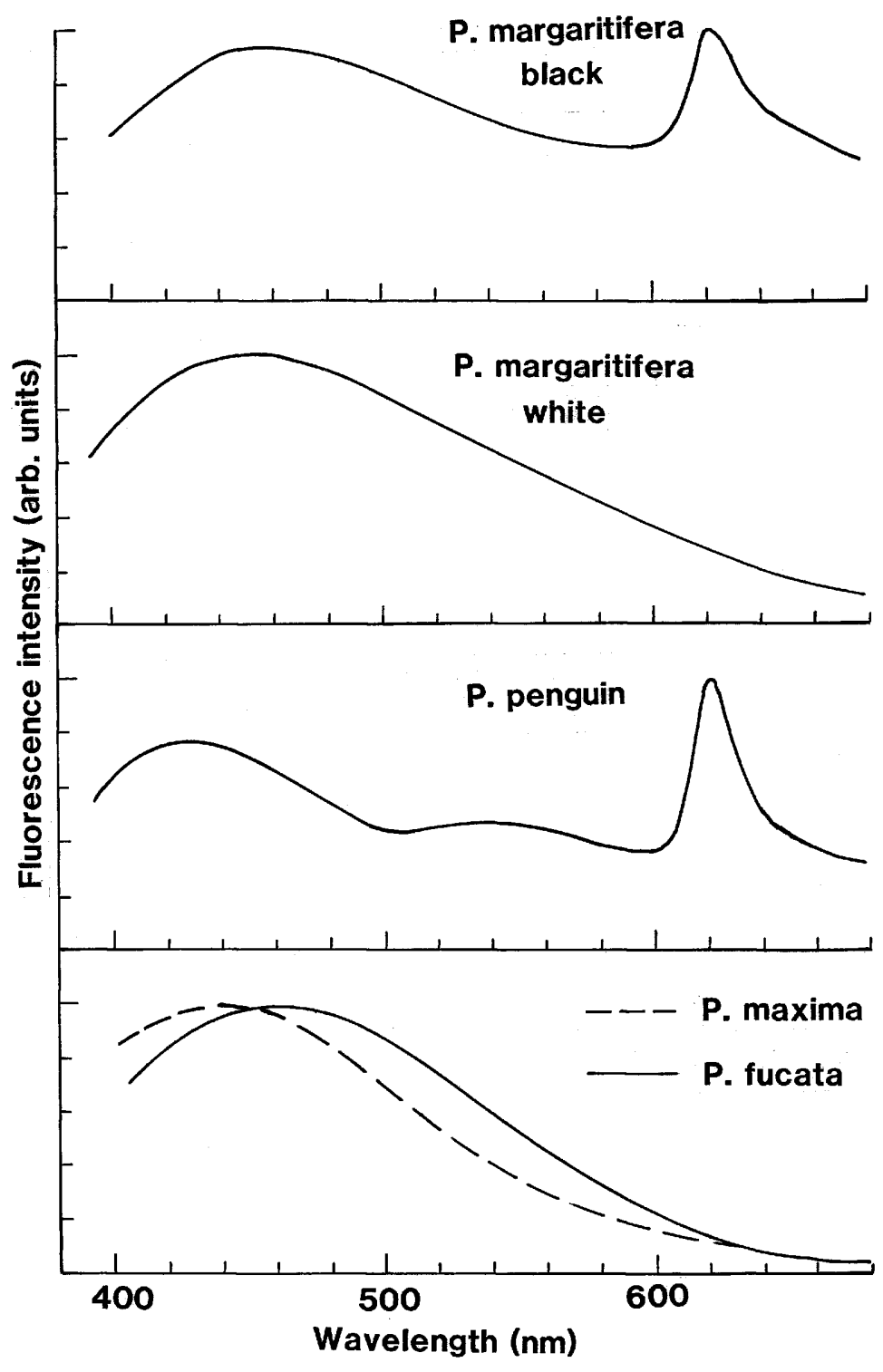

Fig. 2




Fig. 3

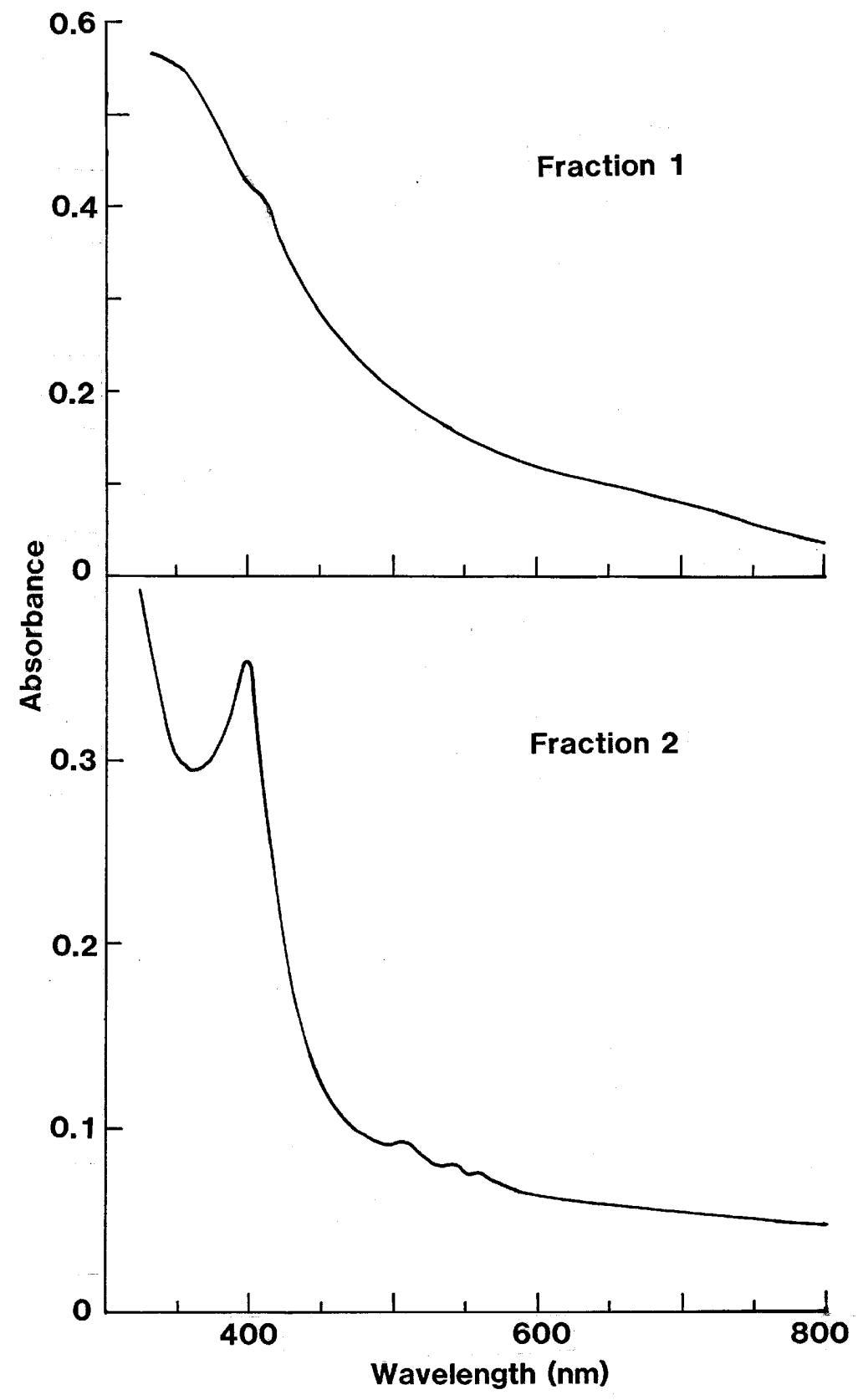


Fig. 4

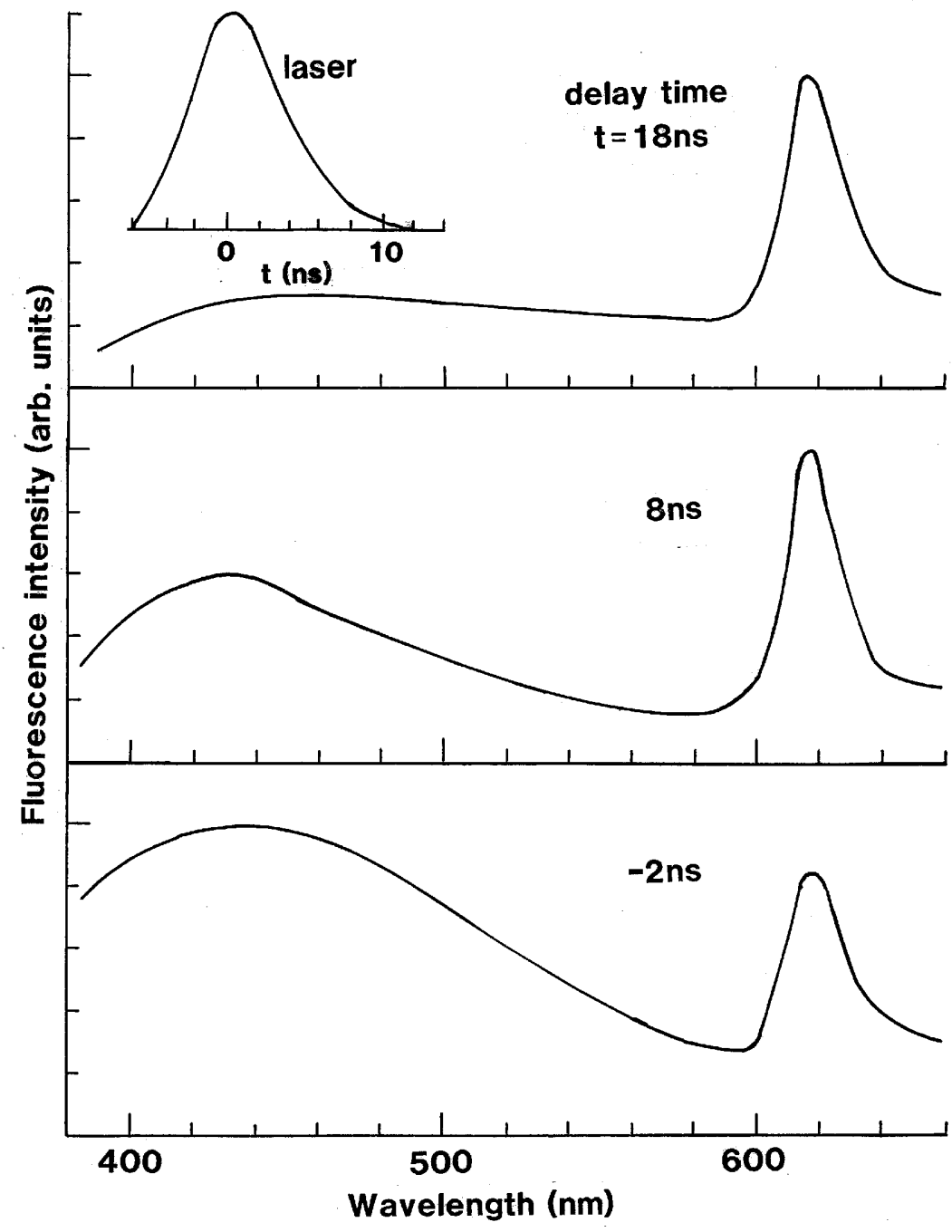

decay time of $620 \mathrm{~nm}$ band is about $12 \mathrm{~ns}$ 
Fig. 5

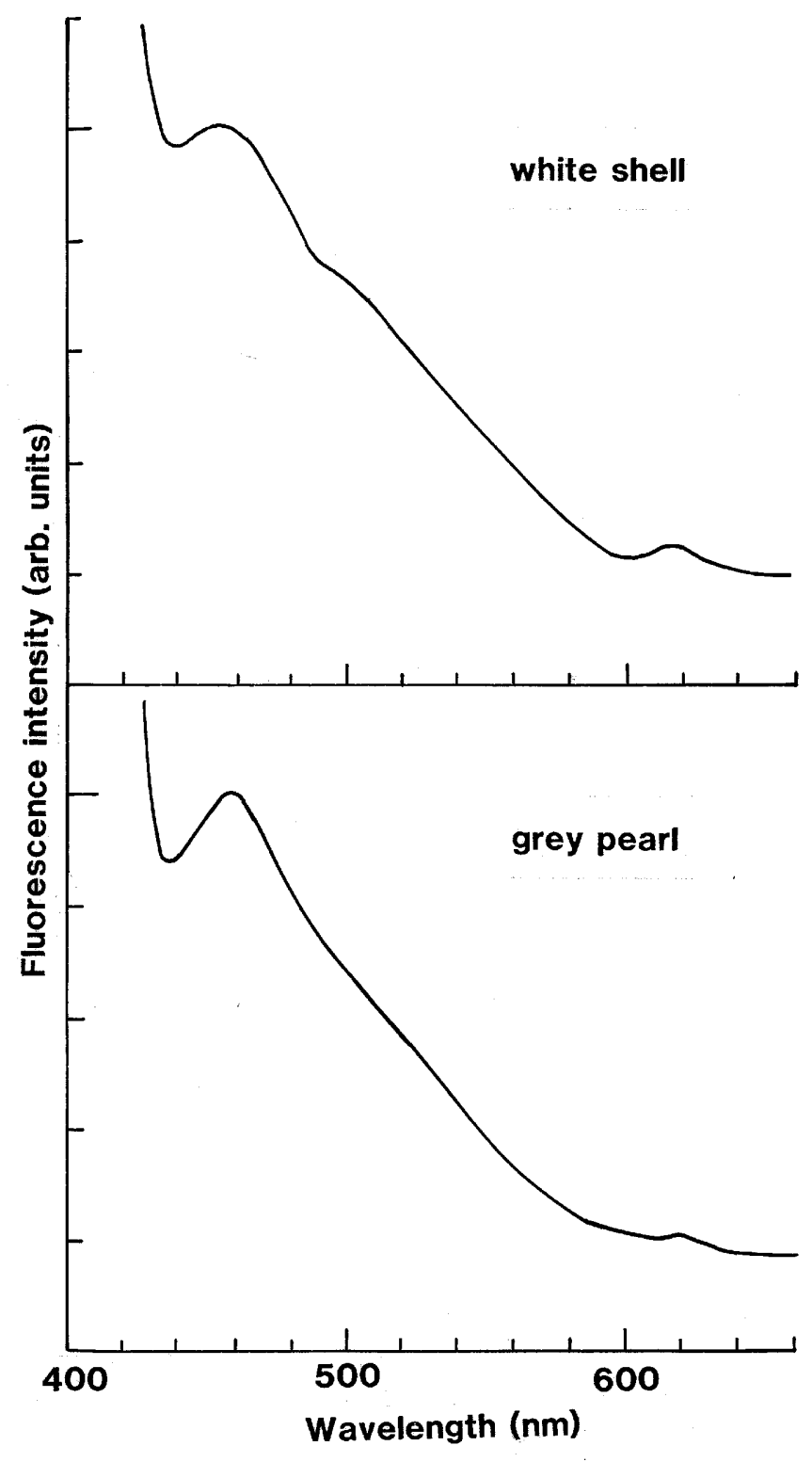


Fig. 6

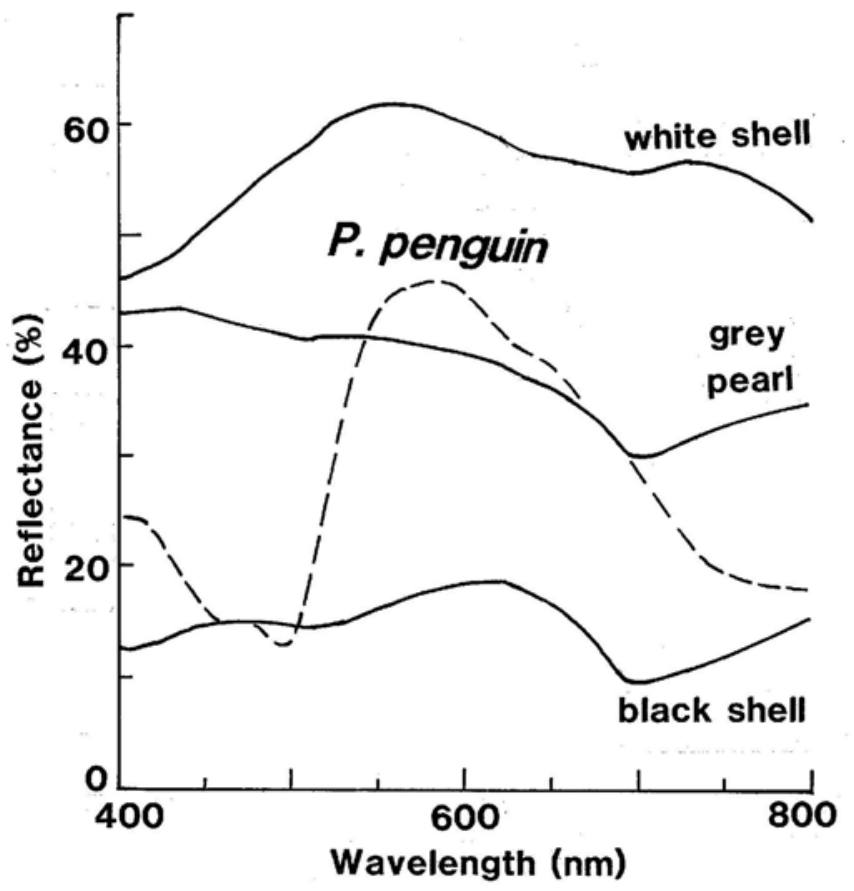

Fig. 7

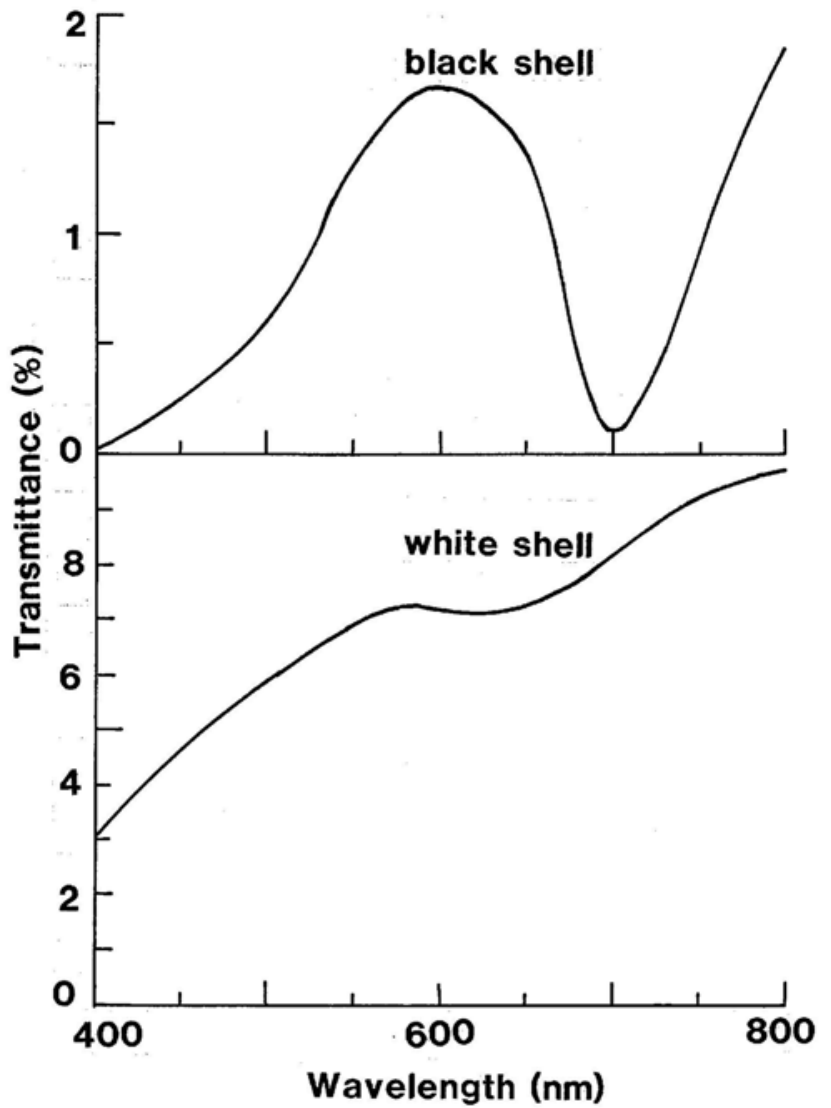


Fig. 8

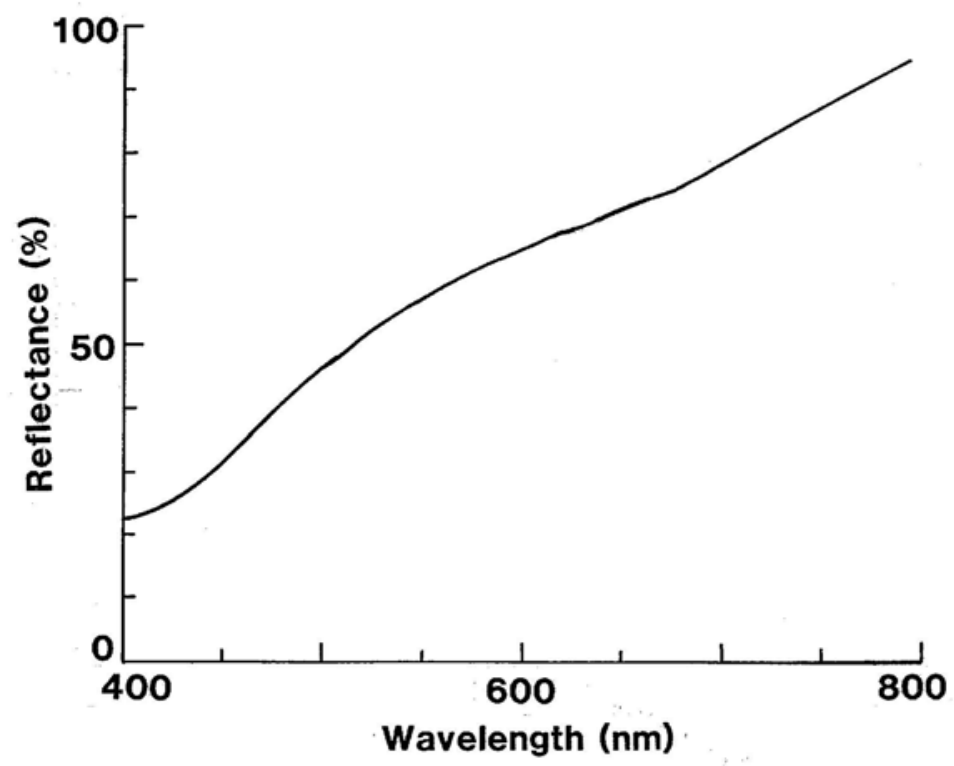

